Article

\title{
On the Importance of Combined Scratch/Acoustic Emission Test Evaluation: SiC and SiCN Thin Films Case Study
}

\author{
Jan Tomastik ${ }^{1, *} \mathbb{1}$, Radim Ctvrtlik ${ }^{2, *} \mathbb{1}$, Martin Drab ${ }^{3}$ and Jan Manak ${ }^{4}$ \\ 1 Regional Centre of Advanced Technologies and Materials, Joint Laboratory of Optics of Palacky University \\ and Institute of Physics of Academy of Sciences of the Czech Republic, Faculty of Science, \\ Palacky University, 17. listopadu 12, 77146 Olomouc, Czech Republic \\ 2 Institute of Physics of the Academy of Sciences of the Czech Republic, Joint Laboratory of Optics of Palacky \\ University and Institute of Physics AS CR, 17. listopadu 50a, 77207 Olomouc, Czech Republic \\ 3 ZD Rpety-Dakel, Ohrobecká 408/3, 14200 Prague, Czech Republic; martin.drab@fjfi.cvut.cz \\ 4 Department of Material Analysis, Institute of Physics CAS, Na Slovance 2, 18221 Prague, Czech Republic; \\ manak@fzu.cz \\ * Correspondence: tomastik@jointlab.upol.cz (J.T.); ctvrtlik@fzu.cz (R.C.); Tel.: +420-585-631-573 (J.T.)
}

Received: 9 April 2018; Accepted: 21 May 2018; Published: 22 May 2018

\begin{abstract}
The scratch test, as probably the most widespread technique for assessment of the adhesive/cohesive properties of a film-substrate system, fully depends on reliable evaluation based on assessment of critical loads for systems' failures. Traditionally used evaluation methods (depth change record and visual observation) may sometimes give misleading conclusions about the failure dynamics, especially in the case of opaque films. Therefore, there is a need for another independent evaluation technique with the potential to complete the existing approaches. The nondestructive method of acoustic emission, which detects the elastic waves emitted during film cracking and delamination, can be regarded as a convenient candidate for such a role even at nano/micro scale. The strength of the combination of microscopic observation of the residual groove and depth change record with the acoustic emission detection system proved to be a robust and reliable approach in analyzing adhesion/cohesion properties of thin films. The dynamics of the gradual damage taking place during the nano/micro scratch test revealed by the combined approach is presented for $\mathrm{SiC}$ and $\mathrm{SiCN}$ thin films. Comparison of critical load values clearly reflects the higher ability of the $\mathrm{AE}$ approach in detecting the initial material failure compared to the visual observation.
\end{abstract}

Keywords: scratch test; acoustic emission; thin films; silicon carbide

\section{Introduction}

Rising demands for modern materials with application-optimized physical properties are the main driving force in contemporary material engineering. The use of surface films and coatings is a logical and successful solution to this challenge as materials and components interact with their surroundings through their surface. Nowadays, various types of physical vapor deposition (PVD), chemical vapor deposition (CVD), and sol-gel techniques are used for production of films in nearly all branches of industry [1-9]. Regardless of the primary functional property of the films predetermined by their application, their mechanical properties and stability are also essential for their long-term service. Mainly, adhesion of the films to the substrate is the primal parameter governing the performance of the system.

The definition given by the American Society for Testing and Materials (ASTM) says that "adhesion is the state in which two surfaces are held together by interfacial forces which may consist of valence forces or interlocking forces or both" [10]. This "basic or also theoretical adhesion" depends on the 
electrostatic, chemical, and/or van der Waals forces, which act on the whole contact surface between film and substrate. However, the measured "experimental adhesion" exhibits significantly smaller values due to structural voids and material peculiarities (internal stresses, porosity, homogeneity, roughness of contact area, etc.) and also due to the effects associated with the measurement methods (fixing of the sample, tangential forces, experimental errors, etc.) as well as the rigidity of the testing instrument itself $[11,12]$. Various experimental techniques have been introduced, aiming for not only the qualitative differentiation between the measured samples but also for the quantification of adhesion forces. In addition to the non-mechanical methods (thermal, nucleation, x-ray diffraction, etc.) [13-15], the more direct mechanical methods (scotch tape, bend test, laser spallation, direct pull-off, etc.) [12,15-18] have been used with varying success. Nevertheless, their mutual comparison is questionable and the level of proximity to the basic adhesion varies. It is mainly the difficulty of the experimental approaches and the cost of measurement which makes many of them impractical solutions [19-21].

Among all of these techniques, the instrumented scratch test method is probably the most widespread technique for assessment of adhesion/cohesion parameters of a film-substrate system [22-25]. This traditional mechanical method is based on the interaction of the diamond testing probe with the coated surface. A probe with a linearly increasing load is pulled across the measured surface, while depth change is continuously measured. A moving indenter induces stresses in the tested film, which in reaction deforms elastically and/or plastically. Despite the experimental/principle simplicity, the scratching process is very complex [26-29]. When the deformation is sufficient to overcome the cohesive bonds in the film, cracks emerge. When the adhesive forces between film and substrate are surpassed, delamination or chipping of the film occurs. The objective of the scratch test is to find the so called critical loads $\left(L_{C}\right)$, which are the forces inducing the typical failure modes. The great advantage of the scratch test stems from its possibility of tailoring the experimental parameters (normal load, indenter size), allowing the position of the von Mises stress maximum to be specified and, in turn, the sensitivity of the test for specific depth regions to be optimized. With increased load, the position of the von Mises stress is shifted to the substrate and this is more pronounced for larger indenter radii [30]. The proper dimensioning of the test can be performed based on Finite Element Modelling (FEM) [31-36] or analytical models [30]. Localizing the von Mises stress maximum-which in fact is supposed to be higher than yield stress-to the film-substrate interface is recommended when adhesion is the main concern. Due to its universality, the scratch test has spread from research to industrial use. The scratch test has been proved to be an efficient method for evaluation of adhesion and cohesion properties of various types of coated systems including hard protective coatings [37-40], optical thin films [41-43], medicinal coatings [44], and so on. Besides, it has been shown that also other types of materials can be beneficially explored such as plasma spray coatings [45], where for example the cohesion of individual splats can be studied [46]. In general, the tribological properties, including wear, of any material [47] can be studied as shown for example by Sola et al. for surface modified steel [48-50].

The evaluation of the critical loads is traditionally performed through the microscopic observation of the residual scratch groove and the indenter depth change record. While both techniques can be adequate in some cases on their own, they are often and beneficially used in combination to obtain more precise results. Nevertheless, even their combination may fail in the accurate determination of the critical loads in specific cases [30]. As a result, misleading conclusions about the film's durability and, in turn, improper inputs into the service life estimation and optimization process can be deduced. For example, consider the case of an opaque durable film on a hard brittle substrate (e.g., silicon), that is often the scenario in the semiconductor industry. In this case the stresses introduced during the scratch test can induce film and/or substrate cohesion failure or the adhesion failure between both components. Especially in the last two cases, the failure type classification and critical load identification can be misleading. When cohesive strength of the film itself is strong enough, the film can endure even after the first initiation of adhesion failure or substrate cohesion failure until it 
breaks away from the substrate at the latter part of the scratch track. As a result, the point of the film detachment is incorrectly identified as initial failure mode in the measured film-substrate system.

One of the possible solutions to overcome the abovementioned shortcomings of the standard evaluation techniques may be detection of acoustic emission (AE) signals recorded during the scratch test [51]. In general, acoustic emissions are elastic waves that are emitted during cracking or other irreversible changes in a material's internal structure. Although the AE method was already introduced in the scratch test some decades ago, its broader use has been hampered by insufficient hardware, impractical solutions, or weak software support for analysis. To the best of our knowledge, the use of AE during mechanical testing of thin films has been restricted mainly to thicker films (more than $5 \mu \mathrm{m}$ ) [52] or high normal loads (more than $1 \mathrm{~N}$ ) [52-54]. Besides, these tests were often performed with spherical indenters of large radii (more than $100 \mu \mathrm{m}$ ) [52,54]. As a result, the von Mises stress maxima were shifted to the substrate, that is, further from the film-substrate interface. The analytical potential of the AE method is however extremely high. Combined use of AE detection with traditional techniques creates an unmatched approach for not only the detection of the initial cracks in the tested system, but also for deeper analysis and understanding of the failure modes' dynamics and causality during the scratch test.

Although the $\mathrm{SiC}$ thin films and their doped modifications are very promising materials in many structural applications and their mechanical properties have been studied thoroughly [55-57], there is a lack of systematic information about their deformation response to the scratch loading and adhesion strength. The tribological properties of various types of $\mathrm{SiC}_{x} \mathrm{~N}_{y}$ films and coatings have been studied and compared [57-61]. However, in most cases the deformation mechanism or the failure dynamic were neglected.

In this paper a combined scratch test evaluation based on the synergic use of the AE signal record along with the confocal microscope visual observation of the residual groove and the analysis of depth change record is presented. Hard a-SiC and a-SiCN thin films with the $\mathrm{Si} / \mathrm{C} \sim 1$ on brittle Si substrates are explored and used as a demonstration system. The dynamics of the films' gradual damage is revealed and the individual failure modes are distinguished.

\section{Acoustic Emission Introduction}

Acoustic emission (AE) is the phenomenon describing the emission of elastic waves generated by release of internally stored energy during abrupt permanent changes in materials. Significant AE accompanies the initiation and propagation of cracks in rather brittle materials, however weaker $\mathrm{AE}$ also accompanies sliding of dislocation (slip planes) during deformation of crystalline material $[62,63]$.

AE sensors have been routinely employed at macro-level for monitoring of structural strength of constructions and pipelines. They have been used for health monitoring and detecting of cracks in large pressure vessels, for control of water cooling pipeline systems in nuclear power plants, monitoring corrosion of reinforced concrete, or as failure control of important structural points [64-70]. Acoustic emission based methods also found their way to biological research with a drought stress experiment on leaves of common European trees [71]. Although the use of AE methods at macro scale has been successfully proved to be a reliable tool, their application at smaller scales is still a challenging task in terms of construction and data interpretation. Nevertheless, AE may provide a large amount of unique information about the structural integrity of a material/device and is still a very live topic [72,73].

The implementation of an acoustic emission method in the evaluation of the scratch test has been accompanied by various technical solutions throughout history. First, AE sensors based on accelerometers were introduced in the 1980s. Even with a cut-off frequency of around $50 \mathrm{kHz}$ they were strongly disturbed by ambient mechanical vibrations, such as footsteps, motors' movement, and surface roughness during the tip move. This technology has been overcome by the utilization of the resonant $\mathrm{AE}$ sensors working at a frequency range of $30-1000 \mathrm{kHz}$ due to the fact that the majority of the parasitic signals are rather low frequency signals below $50 \mathrm{kHz}$ [74]. 
Localized stress fields and processes in a material during the scratch test results in acoustic emissions with frequencies up to $1 \mathrm{MHz}$, which leads to the demand for broadband piezoelectric detectors. The piezoelements are nowadays used in nearly all cases of modern AE systems. The piezoelectric response of used materials allows fabrication of compact sensors compatible with the majority of commercial scratch testers $[75,76]$. It should be noted that special sensors can be used even at elevated temperatures up to $1150{ }^{\circ} \mathrm{C}$ [77].

Since a scratch test on thin film is a sensitive micro-technique that can be affected by its surroundings, specific demands are made on the experimental arrangement. During the test, a micrometer radius tip interacts with the tested thin film causing a localized deformation zone with a size of hundreds of nanometers. The appropriate position of the AE sensor near the emission zone during the scratch test is of the highest importance. Small sensors can be placed on the mount of the scratching tip $[75,78,79]$ or glued to the surface of sample [80,81]. Both solutions are often used in practice and both possess some advantages and disadvantages. A sensor attached to the tip benefits from its proximity to the material interaction volume from where the AE signal is emitted. However, the disadvantage is a small contact surface between the tip and the film's surface, which eventually transmits only a minor part of the signal that spreads omnidirectionally from the point of origin. Also the fixing procedure of the sensor itself is an issue, as its weight can interfere with the correct movement of the tip. In addition, such mounting makes manipulation during tip's change more difficult. Alternatively, the AE sensor can be directly placed on the sample surface. This approach benefits from its high sensitivity and easy implementation on pre-existing experimental setups. It should be noted that this is a preferable approach nowadays. The mounting position must be chosen appropriately as contact of the sensor with the tip must be avoided. On the other hand, the contamination of sample surface with the used adhesive is undesirable and may be considered as one of the biggest drawbacks. Since both abovementioned approaches possess substantial shortcomings, the use of AE methods in scratch testing has been only marginal and mostly devoted only to very specific case studies, some of which are listed below.

For example, research on AlN coated stainless steel by Choudhary [75] was focused on the use of the AE method as an indicator of a coating's cracking during the scratch test without use of any complex signal analysis. Similar use of the method concerning only the amplitude of the AE signal as a signalization of changes in material was used in bone toughness analysis by Kataruka [82] and research on several types of ceramics coatings $\left(\mathrm{TiB}_{2}, \mathrm{TiN}, \mathrm{Al}_{2} \mathrm{O}_{3}-\mathrm{SiO}_{2}-\mathrm{Cr}_{2} \mathrm{O}_{3}, \mathrm{CrN}\right)$ by Ishikawa [83], Bhansali [84], Sekler [85], and Jensen [51].

A more sophisticated approach focusing on energy (wavelet transform) rather than amplitude of the AE signal was adopted in Piotrkovsky's research related to scratch test behavior of commercial galvanized coatings [86,87], grit scratch tests on aerospace alloys by Griffin [88-90], as well as a different type of tests on reinforced concrete by Sagasta, Zitto, and Piotrkovsky [91,92]. Research on deformation processes during scratch tests of molybdenum and tungsten by Zhou [93] also uses analysis of more complex outputs of the AE record. The deformation response of TiN thin films and the underlying Si substrate under sliding indentation was investigated by Benayoun [53] or Shiwa [94]. To reveal the substrate deformation, the film was chemically etched [94]. The combination of Focused Ion Beam (FIB) cross-sectioning of the residual groove and the AE was used to study the effect of substrate surface finish on the scratch induced failure mechanism of TiN on WC-Co substrate by Yang et al. [54].

It is not surprising, that the amount of data obtained from AE is massive. One of the solutions to handle the analysis of such an amount of data is the use of artificial neural networks [70,90].

\section{Acoustic Emission Signal}

The amplitude and frequency of AE events are functions of sample's material properties and geometry, and also depend on the source of $\mathrm{AE}$. The complete record of the $\mathrm{AE}$ signal represents a large amount of data that may be inappropriately sizeable and too detailed for basic determination of critical events representing various types of film-substrate failure. It is more common to use a time compressed 
AE record, a so-called Envelope (see Figure 1a), that can be directly compared with the depth change record and the microscopic image of residual scratch groove. To visualize the dynamic of gradual damage of the tested material, one can choose the amplitude threshold and trace the number exceeding in full time resolution in the form of Cumulative counts (see Figure 1b). A full-resolution record of a specific $\mathrm{AE}$ event corresponding to the failure event occurring during the scratch test is called the Hit (see Figure 1c). It is defined by the amplitude and time thresholds. Using the Fourier transformation, a Hit's spectrum can be obtained (see Figure 1d). In addition to the hit's shape, its frequency spectra may be considered as a possible "fingerprint" of a particular type of failure mode in the film-substrate system [63].

(a)
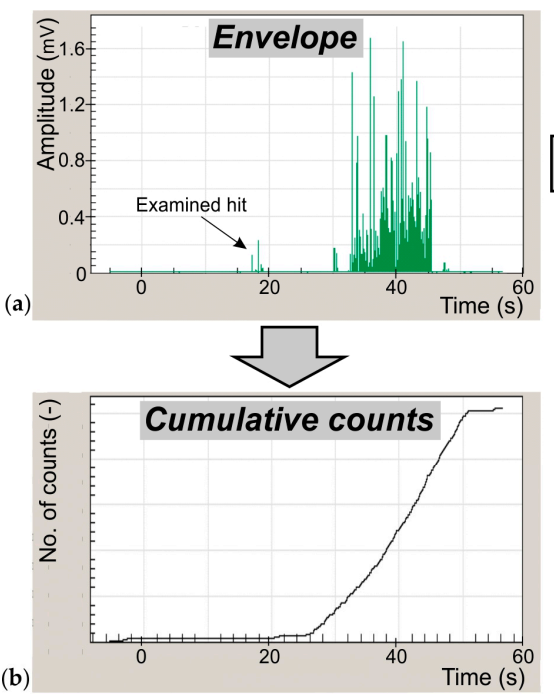

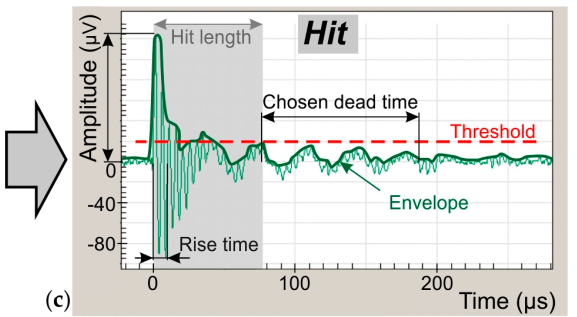

(c)

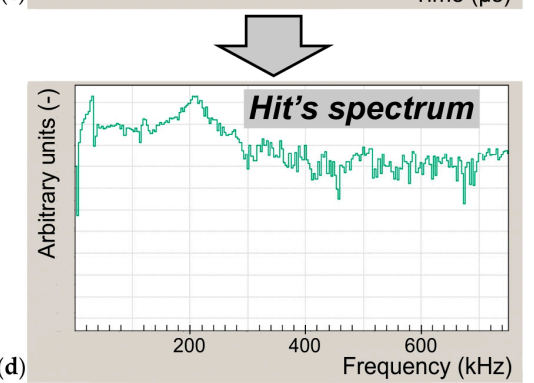

Figure 1. Parameters obtained from an acoustic emission (AE) analysis. (a) Compressed signal of complete AE record in form of the Envelope with (b) tracked exceedances of chosen amplitude threshold in form of the Cumulative counts. (c) Full time resolution AE event called Hit with its threshold described and (d) exported Spectrum.

\section{Instrumentation and Methods}

\subsection{Acoustic Emission Setup}

The acoustic emissions were detected using the ZEDO system (Dakel, Prague, Czech Republic) with the $10 \mathrm{MHz}$ signal sampling rate allowing detections of AE signal variations with sub-microsecond resolution. The high dynamic range of the ZEDO system brings the possibility to register and analyze both the strong AE signals (complete breakage of the film) as well as weak AE signals originating from the small initial cracking. The AE record synchronized with the depth-change record allows accurate assignment of individual AE events to the microscopically observable failures in the residual scratch or the events in depth change record.

The samples were loaded on the special AE sample holder of our own design with the inbuilt high-sensitivity piezoelectric sensor and the dedicated preamplifier. Its design reflects the needs of high sensitivity and universal applicability and addresses the need of simple sample manipulation and avoiding the surface contamination by adhesive. Samples can be easily fixed to the holder using traditional cold or warm bonding (glue or wax, respectively).

\subsection{Scratch Test Setup}

The scratch tests were performed using the fully calibrated NanoTest instrument (MicroMaterials Ltd., Wales, UK) with the diamond cono-spherical Rockwell indenter with an actual radius of $9 \mu \mathrm{m}$. Samples were fixed on the special AE holder using a low temperature wax. In fact, the AE holder 
resembles the regular holder, except for the cable transferring the electric signal to the AE main unit (see Figure 2).

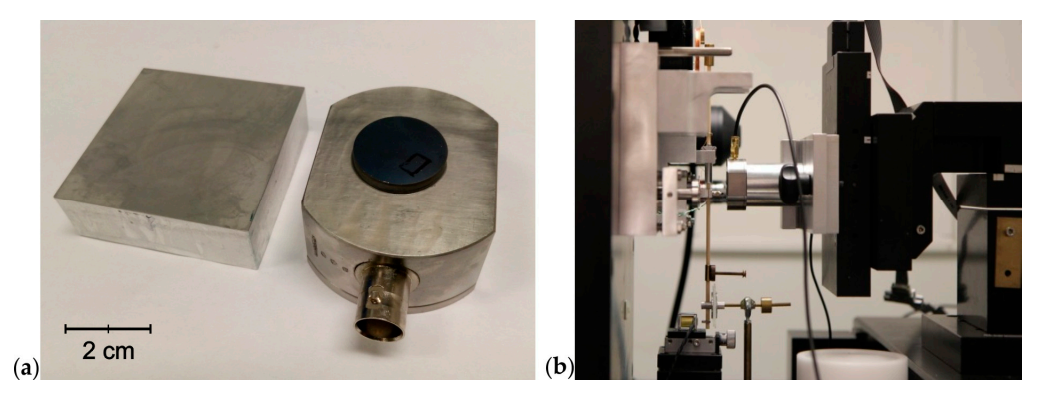

Figure 2. (a) Comparison of sample holders: traditional passive $5 \mathrm{~cm} \times 5 \mathrm{~cm}$ specimen holder from duralumin (left) and the AE sample holder with built-in acoustic emission sensor and pre-amplifier (right). (b) Implementation of the AE holder into the NanoTest instrument.

During the ramped-load scratch tests the load on the indenter was linearly increased until the maximum of $500 \mathrm{mN}$. The experiments were performed as a 3-pass test, where the initial topography pass with very low topography load of $0.02 \mathrm{mN}$ was followed by on-load scratch, after which came the final topography pass scanning the worn profile. The residual scratch groove was thoroughly explored using the laser scanning confocal microscope OLS LEXT 3100 (Olympus, Tokyo, Japan). The cross-sections of the residual scratch groove were made using the FEI Quanta 3D (Hillsboro, OR, USA) Dual-Beam SEM/FIB system with a $\mathrm{Ga}^{+}$ion source. Each test was repeated at least five times for sufficient data statistics and sample homogeneity. The evaluation of the instrumented scratch test was carried out based on a combination of three methods: (i) the depth change record, (ii) residual scratch imaging, and (iii) the acoustic emissions record.

\section{Advanced Scratch Test Evaluation}

The strength of the simultaneous $\mathrm{AE}$ detection during the scratch test supplementing the traditional methods will be demonstrated for a- $\mathrm{SiC}_{x} \mathrm{~N}_{y}(y \geq 0)$ films magnetron sputtered on silicon substrates. These $\mathrm{SiC}$ and $\mathrm{SiCN}$ films, depending on actual structure and composition, can possess high hardness [95], resistance to chemicals and abrasion even at high temperatures [96,97], as well high radiation resistance [98]. This excellent combination of physical and chemical properties makes them a very promising candidate for protective high temperature coatings $[56,99,100]$. It is especially the doping capability that allows tailoring of physical and material properties. For example, the imposed brittleness of the pure $\mathrm{SiC}$ can be partially suppressed by incorporation of $\mathrm{N}$ into the $\mathrm{SiC}$ structure. Besides, the band gap can be tuned by N content [101]. Since the a-SiC and a-SiCN films are often used in structural applications, their durability (including adhesion and cohesion) is of the highest importance and hence it has been studied extensively even in situ at elevated temperatures [102-104].

\subsection{Combined Approach-Dynamic Revealed}

A typical example, where the traditional approach lead to the incorrect determination of critical loads, can be instructively presented on two scratch tests performed on the SiC thin film (see Figure 3). A microscopic image of the first test's residual groove shows gross spallation beginning at the point marked by number "2", see Figure 3a. Small cracks inside the residual groove were detected with difficulty using higher magnification (not shown here) in the earlier stages starting from the point labeled by number " 1 ". However, the acoustic emission record (see Figure $3 b$ ) shows an abrupt amplitude increase in the 25th second, indicating that the very first cracking in the film-substrate system $\left(L_{C 1}\right)$ occurred sooner than expected from the microscopic observation (marked by number " 1 " in Figure 3a). Besides, analysis of the depth change record reveals, that point " 2 " - considered as the onset of the gross spallation-is determined incorrectly, see Figure 3c. While the red curve representing 
the final topography indicates onset of the film failure already around the 340th micrometer of the track, the blue on-loaded scratch curve abruptly drops later, around the 380th micrometer. Taking all of these pieces of information into account, the dynamic of the film damage can be revealed and the onsets of the film-substrate failures can be evaluated correctly. In this particular case, film spallation occurs in the 380th micrometer (now marked as $L_{\mathrm{C} 2}$ ) both in the forward direction and even partially backward until the point " 2 ".

Similarly to the previous example, relying solely only on the microscopic analysis (Figure 3d) inevitably leads to the misleading assumption that large area film delamination occurred at the point marked " 1 " and spread until the point " 2 ". However, the depth change record analysis shows different dynamics of the film's failure, see Figure 3f. It is important to note that on-load depth as well as final depth records must be considered. The course of blue curve (on-load), representing the evolution of the tip penetration depth with an increasing normal load, increases linearly with a load until a sudden drop to a depth of around $8 \mu \mathrm{m}$ occurs at 320th micrometer of the track, also labeled as the point " 2 ". On the other hand, the red curve representing final topography profile shows surprising information: the depth curve drops abruptly to a depth of two microns around the 180th micrometer (point marked " 1 ") and remains steady until point " 2 ". Based on previous findings, it can be correctly determined that film delamination occurs at the moment of reaching point "2" (now designated $L_{\mathrm{C} 2}$ ), where the film delaminates significantly in the reverse direction until point " 1 ". The last piece of information for full understanding of the failure dynamics is provided by the acoustic emission record. A single peak can be seen around 17th second of the AE record caused by the single crack in the film (see Figure 3e, position corresponds with the point " 1 " from the microscopic image Figure $3 \mathrm{~d}$ ). Its origin stems from a local growth defect on the film surface actually revealed in the initial topography (see green curve in Figure 3f). The backward spallation of the film, which detached at point " 2 " $\left(=L_{C 2}\right)$, was therefore stopped by this crack. The most interesting part in AE record can be seen around 22nd second, where signal amplitude rises again. Subsequent comparison with the microscopic record (see Figure 3d) points out cracking initiated at the film-substrate interface, which was still at the time covered by the coating (as explained above). The onset of this substrate cracking is assigned to the critical load $L_{\mathrm{C} 1}$.

Since the position of $L_{C 1}$ from this second scratch actually matches the $L_{C 1}$ in the first scratch, it can be concluded that substrate cracking below the still adhering film is indeed the very first failure event in all tested film-substrate systems. All this was revealed only through the combined use of the three evaluation techniques of ramped scratch test.
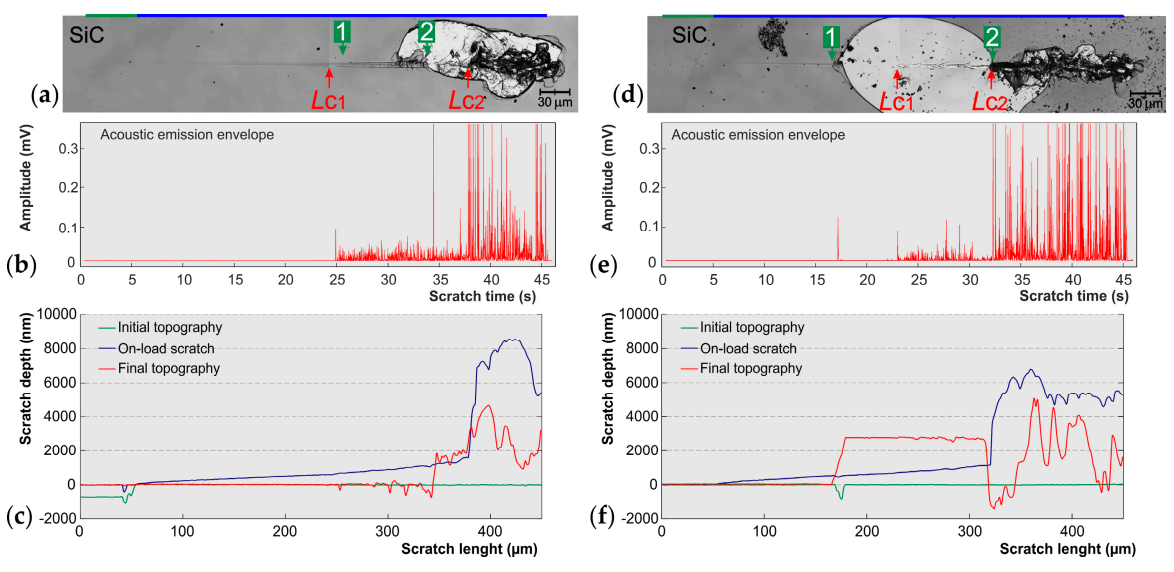

Figure 3. Advanced analysis of two ramped scratch tests on 00SiC sample with $(\mathbf{a}, \mathbf{d})$ the microscopic records, $(\mathbf{b}, \mathbf{e})$ the acoustic emissions records and $(\mathbf{c}, \mathbf{f})$ depth change records.

\subsection{Extended Approach-Failure Type Revealed}

The information content obtained from the scratch test and its reliability can be further enhanced via analysis of the residual groove by SEM-EDX mapping. The strength of such a complex approach 
can be manifested on the a-SiCN thin films annealed in air. It is well known that $\mathrm{SiCN}$ films with higher $\mathrm{N}$ content are prone to oxidation, especially at higher temperatures above $1000{ }^{\circ} \mathrm{C}$, where the $\mathrm{SiO}_{x}$ oxidation layer is formed [105]. This is another instructive example of how the sole visual observation may be misleading in terms of evaluation of scratch test.

Typical residual scratch groove for the SiCN film with the N content of 36 at \% is shown in Figure 4. At the first glance, using only microscopic evaluation one may conclude that coating seems to be scratched through in the area highlighted by the violet rectangle, while the first critical load $L_{\mathrm{C} 1}$ is practically undetectable even if combined with the depth change record. Subsequent detailed analysis based on the depth profiling of the 3D high resolution confocal microscope image and especially the electron microscope (see Figure $4 \mathrm{~d}$, e, respectively) revealed the penetration of the oxide $\mathrm{SiO}_{x}$ surface layer only (thus marked $L_{\mathrm{Cox}}$ ), while the remaining unoxidized $\mathrm{SiCN}$ film remained intact. The exact point of scratching through the oxide layer was confirmed using electron microscopes' EDS mapping technique [106] as can be seen from Figure 4e, where the green arrow indicates the direction of the linear mapping profile inside the residual groove; the corresponding spectra are shown below. The blue dashed line of oxygen signal drops exactly at the point where $\mathrm{SiO}_{x}$ is scraped off. Another detail from the latter part of scratch track (see Figure 4d) shows the further evidence of the detached $\mathrm{SiO}_{x}$ layer even with its thickness evaluation. Perpendicular profile using calibrated confocal microscope shows a sharp transition between the $\mathrm{SiO}_{x}$ layer and the free surface of the $\mathrm{SiCN}$ film. Step measurement indicates thickness of $\mathrm{SiO}_{x}$ layer of $t_{0}=100 \mathrm{~nm}$. The coating itself proved to be unharmed since its plastic deformation at the deepest point of the residual groove is $t_{\mathrm{r}}=400 \mathrm{~nm}$, which still does not reach the full coating thickness of $2.6 \mu \mathrm{m}$. Moreover, the acoustic emission record clearly shows signal increase around 33th second. This is probably the very same failure mode caused by the film-substrate interface cracking, as described in the previous case on SiC samples (shown in Figure 3) and evidenced in the FIB-milled longitudinal cross-section. The lateral and median cracks are clearly identified in the film and substrate as can be seen in Figure 5. A detailed inspection of the SEM image shows no evidence of through-thickness cracking as all the cracks were stopped within the film. This may be related to the compressive stress in the films [56]. The initial cracks occurrence coincides well with the critical load $L_{\mathrm{C} 1}$ obtain from the AE record. With the increasing load, the cracking in both the film as well as the substrate is more pronounced as shown on the perpendicular cross-section, see Figure 5.

(a)

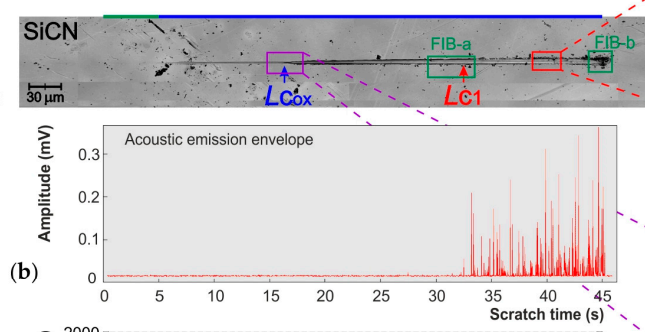

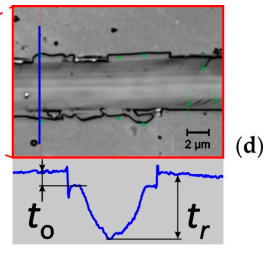

(d)
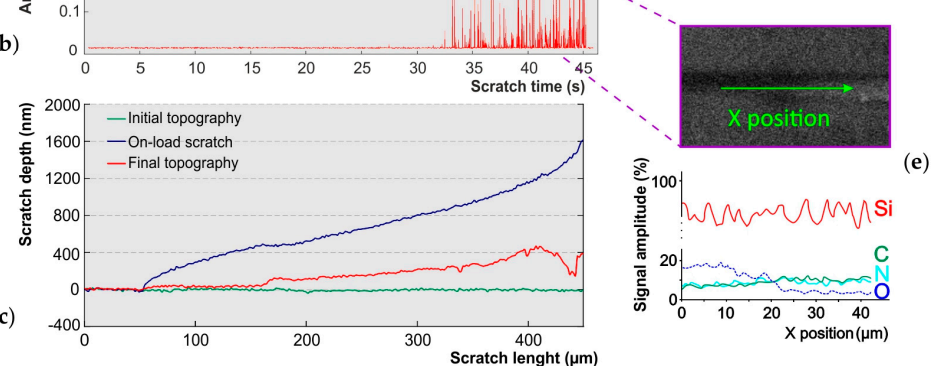

Figure 4. Detailed analysis of selected scratch test on sample SiCN with an oxidized surface using (a) microscopic record, (b) the acoustic emission record and (c) the depth change record. Detail (d) shows profile measurement of $\mathrm{SiO}_{x}$ oxide film thickness and detail (e) shows the oxide $\mathrm{SiO}_{x}$ film first penetration using the SEM-EDS linear mapping. 

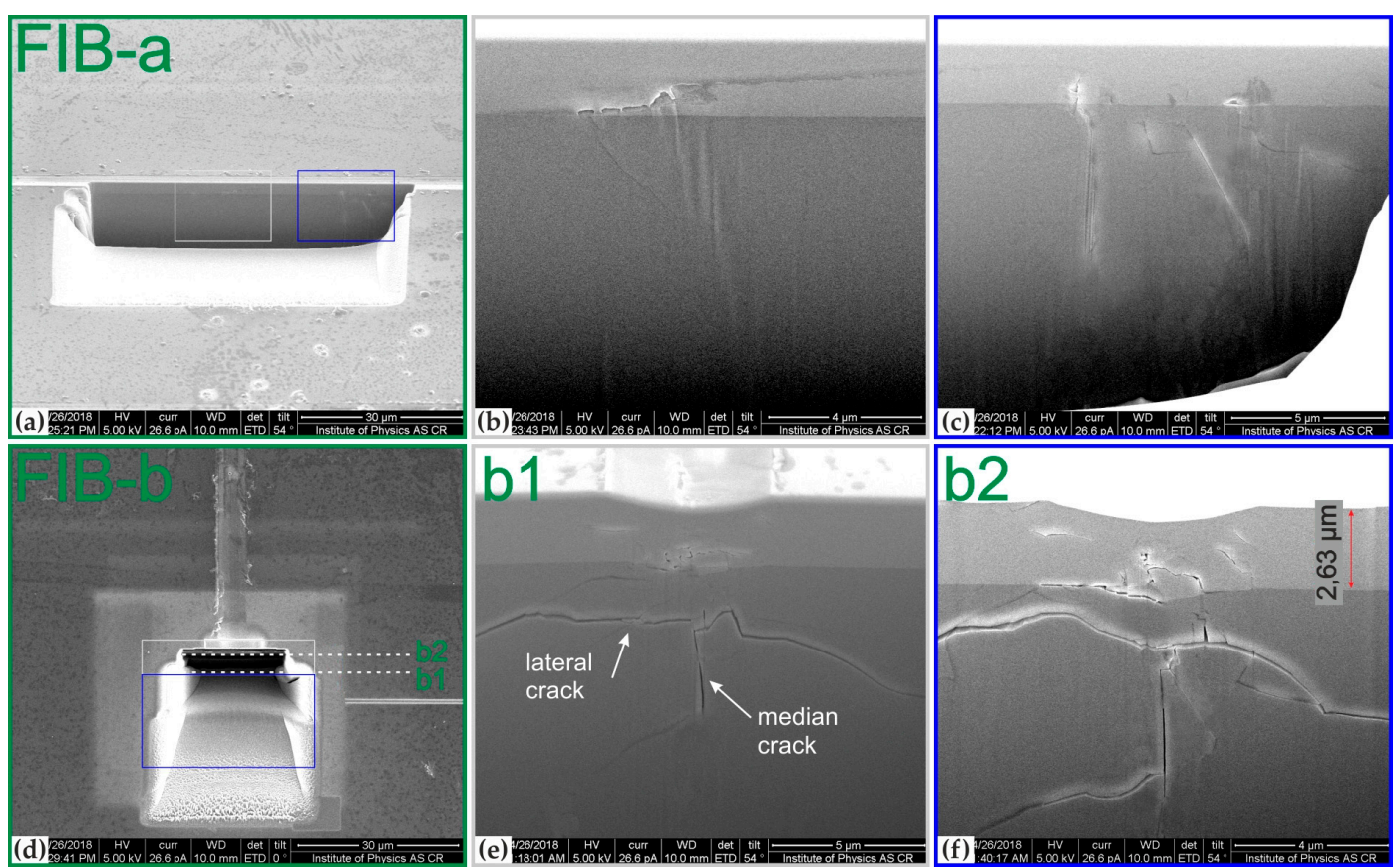

Figure 5. SEM images of the Focused Ion Beam (FIB) milled on the SiCN film for the(a) longitudinal cross section in the area of $L_{\mathrm{c} 1}$ with $(\mathbf{b}, \mathbf{c})$ details and $(\mathbf{d})$ the perpendicular cross section of the final part of the residual scratch groove with $(\mathbf{e}, \mathbf{f})$ two successive cross-sections.

\subsection{AE as a Tool for First Failure Detection}

The strength of the AE method in terms of the very first failure detection during the scratch test is clearly manifested by the comparison of values of critical loads evaluated by in situ AE and visual observation methods for $\mathrm{SiC}$ and $\mathrm{SiCN}$ thin films, see Figure 6. The as-deposited as well as air annealed films $\left(700,900\right.$ and $\left.1100{ }^{\circ} \mathrm{C}\right)$ were explored. The primary goal was to test the effect of annealing temperature on tribological properties of these films with potential use for high temperature protective purposes. Introduction of nitrogen into the $\mathrm{SiC}$ structure led to the improvement of scratch resistance of originally deposited and also annealed coatings. However, the main finding in the context of combined scratch test evaluation described in this article is that the sensitivity of acoustic emissions exceeded the visual microscopic method in all cases. Critical loads obtained by the AE method were always lower (=detected sooner) than the microscopic ones. In extreme case the difference in the critical load values reaches $22 \%$.

The use of the AE method as a complementary technique has been proved to be an important step forward in enhancement of the reliability and accuracy of the scratch test evaluation. However, the AE may go far beyond just identification of the very first cracking. The high sampling frequency of modern AE hardware units allows the recording of the AE signal with sub-microsecond resolution. As a result, the individual AE hits representing the particular physical events (cracking, chipping, delamination, etc.) in the film-substrate system can be subjected to a thorough analysis in time as well as frequency domain. Applying such an enhanced approach, it is possible to distinguish between various types of failures. Figure 7 illustrates the difference between the hit representing cracking in the $\mathrm{SiC}$ film only occurring at low load and the combined $\mathrm{SiC}$ film and underlying $\mathrm{Si}$ substrate cracking. The corresponding frequency spectra confirm the different response of the film-substrate system at different loads. Since various types of material failure are frequency dependent it is possible to online monitor and even classify the material/device/component deterioration that further emphasizes the beneficial role of AE method. 


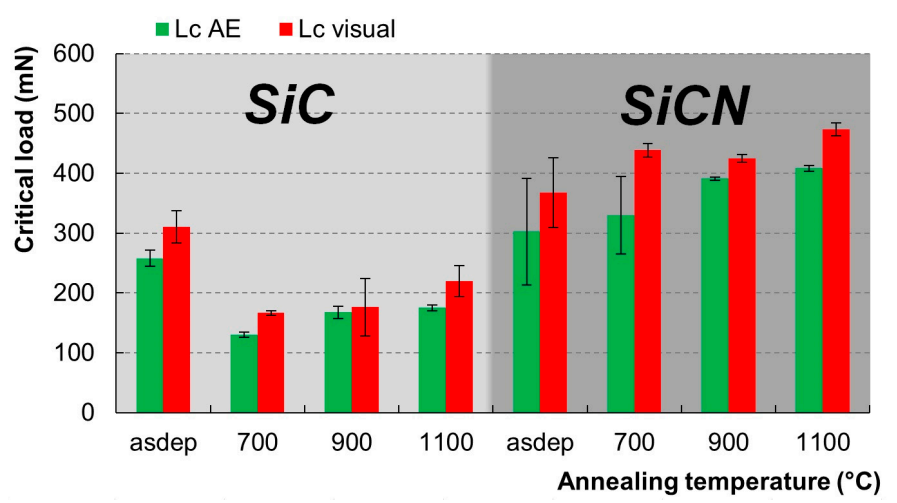

Figure 6. Sum of critical loads of the tested set of samples obtained through the acoustic emission evaluation and the traditional microscopic evaluation of residual scratch. Results show that AE method detected initial failure sooner in all cases.

(a)

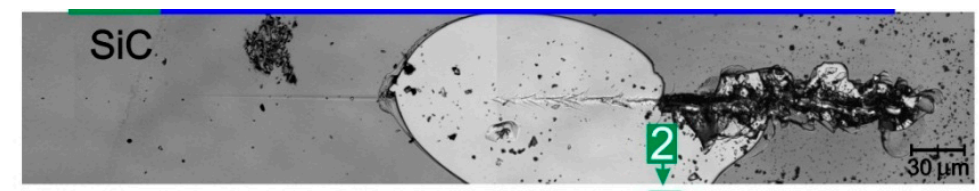

(b)

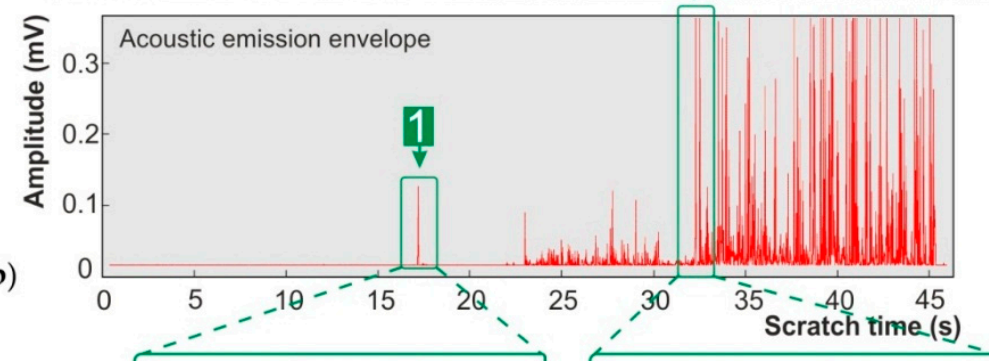

(c)
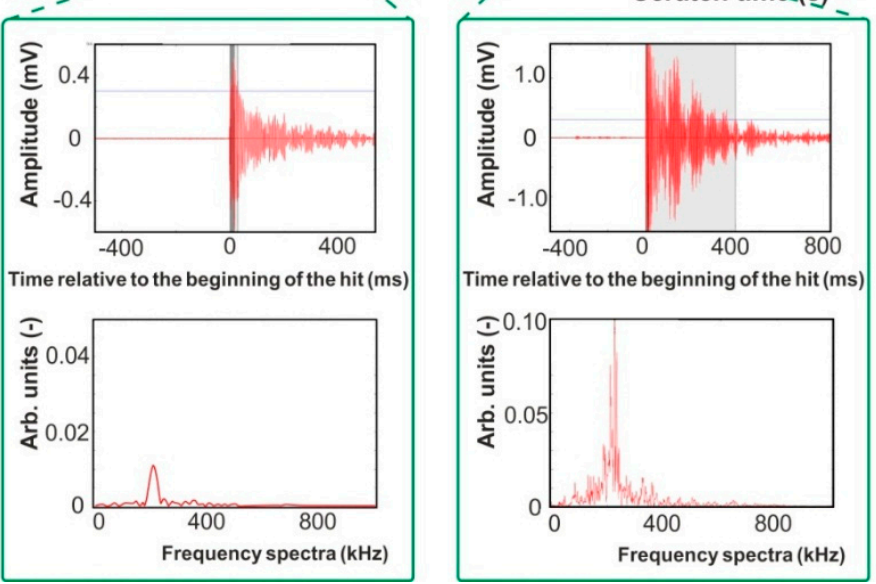

Figure 7. Detailed evaluation of specific observed AE hits. Firstly the microscopic record (a) was compared with the envelope of AE record (b). Then detailed evaluation in form of hit visualization (c) and hit's spectrum (d) of two AE events belonging to the lone film crack (marked "1") and jointly cracking of substrate and film (marked " 2 "). Note the different axis scale in both spectra (d).

\section{Conclusions}

The importance of the combined evaluation of the scratch tests on thin films was presented. In this combined approach, the standardly used visual observation of the residual groove and the depth change record were correlated with the simultaneous acoustic emission (AE) record. The illustrative examples were presented for the $\mathrm{SiC}$ and $\mathrm{SiCN}$ thin films deposited on Si substrates. 
It was shown that proper analysis of the $\mathrm{AE}$ signal and its correlation with standard techniques can significantly increase the informative value of the scratch test. As a result, more reliable conclusions about the material response to external loading can be drawn. The present combined scratch/acoustic emission test evaluation has provided an excellent insight into the physical behaviour of $\mathrm{SiC}$ and SiCN films on silicon substrates during the single asperity scratching contact simulated by the diamond indenter.

The AE method provides unique information that enables the elucidation of the dynamics of the material failure with the potential to differentiate between the film and substrate cracking even at nano/micro scale. The use of $\mathrm{AE}$ in scratch testing is especially beneficial in the case of nontransparent thin films, where the AE signal can reveal subsurface cracking. Ignoring and/or neglecting the internal cracking may dramatically affect the scratch test results/findings. When they are used as input parameters into finite element modeling then the simulation findings can be distorted. Besides, it was shown that AE always detects critical loads sooner than visual observation.

Author Contributions: R.C. and J.T. conceived and designed the experiments, J.T. focused on scratch test experiments - their design, performance, and evaluation. R.C. and M.D. focused on crosschecking of acoustic emission data and advance Hit and Hit's spectra analysis. J.M. performed the FIB milling and SEM. J.T. and R.C. wrote the paper.

Acknowledgments: The authors gratefully acknowledge the support by the Operational Programme Research, Development and Education-European Regional Development Fund, project no CZ.02.1.01/0.0/0.0/ 16_019/0000754 of the Ministry of Education, Youth and Sports of the Czech Republic and the project TH03020245 of the Technology Agency of the Czech Republic, J.T. also acknowledges the Internal Grant of Palacky University (IGA_PrF_2018_009). J.M. acknowledges the support of the project LM2015087 of the Czech Ministry of Education, Youth and Sports.

Conflicts of Interest: The authors declare no conflict of interest.

\section{References}

1. Larsson, M.; Hollman, P.; Hedenqvist, P.; Hogmark, S.; Wahlström, U.; Hultman, L. Deposition and microstructure of PVD TiN- $\mathrm{NbN}$ multilayered coatings by combined reactive electron beam evaporation and DC sputtering. Surf. Coat. Technol. 1996, 86-87 Pt 1, 351-356. [CrossRef]

2. Reddy, I.N.; Reddy, V.R.; Sridhara, N.; Rao, V.S.; Bhattacharya, M.; Bandyopadhyay, P.; Basavaraja, S.; Mukhopadhyay, A.K.; Sharma, A.K.; Dey, A. Pulsed rf magnetron sputtered alumina thin films. Ceram. Int. 2014, 40, 9571-9582. [CrossRef]

3. Kamata, K.; Maeda, Y.; Yasui, K.; Moriyama, M. Preparation of $\mathrm{Si}_{3} \mathrm{~N}_{4}-\mathrm{SiC}$ films by plasma CVD. Int. J. High Technol. Ceram. 1986, 2, 236. [CrossRef]

4. Kleps, L.; Caccavale, F.; Brusatin, G.; Angelescu, A.; Armelao, L. LPCVD silicon carbide and silicon carbonitride films using liquid single precursors. Vacuum 1995, 46, 979-981. [CrossRef]

5. Matthews, A.; Leyland, A. Developments in PVD tribological coatings. In Proceedings of the 5th ASM Heat Treatment and Surface Engineering Conference in Europe, Gothenburg, Sweden, 7-9 June 2000; p. 12.

6. Bescher, E.; Mackenzie, J. Sol-gel coatings for the protection of brass and bronze. J. Sol-Gel Sci. Technol. 2003, 26, 1223-1226. [CrossRef]

7. Kozuka, H.; Almeida, R.M.; Sakka, S. Handbook of Sol-Gel Science and Technology Processing Characterization and Applications V. I: Sol-gel Processing; Springer: New York, NY, USA, 2005.

8. Zajícová, V.; Exnar, P.; Staňová, I. Properties of hybrid coatings based on 3-trimethoxysilylpropyl methacrylate. Ceramics-Silikáty 2011, 55, 221-227.

9. Kuo, D.-H.; Yang, D.-G. Plasma-enhanced chemical vapor deposition of silicon carbonitride using hexamethyldisilazane and nitrogen. Thin Solid Films 2000, 374, 92-97. [CrossRef]

10. American Society for Testing and Materials. ASTM D907-15 Standard Terminology of Adhesives; American Society for Testing and Materials: West Conshohocken, PA, USA, 2015.

11. Pulker, H.K.; Perry, A.J.; Berger, R. Adhesion. Surf. Technol. 1981, 14, 25-39. [CrossRef]

12. Mittal, K.L. Adhesion Measurement of Films and Coatings; VSP: Utrecht, The Netherlands, 1995.

13. Chapman, B.N. Thin-film adhesion. J. Vac. Sci. Technol. 1974, 11, 106-113. [CrossRef]

14. Chopra, K.L. Thin Film Phenomena; McGraw-Hill: New York, NY, USA, 1969. 
15. Campbell, D.S. Handbook of Thin Film Technology; Maissel, L.I., Glang, R., Eds.; McGraw-Hill: New York, NY, USA, 1970.

16. Jacobsson, R. Measurement of the adhesion of thin films. Thin Solid Films 1976, 34, 191-199. [CrossRef]

17. Katz, G. Adhesion of copper films to aluminum oxide using a spinel structure interface. Thin Solid Films 1976, 33, 99-105. [CrossRef]

18. Loh, R.L.; Rossington, C.; Evans, A.G. Laser technique for evaluating spall resistance of brittle coatings. J. Am. Ceram. Soc. 1986, 69, 139-142. [CrossRef]

19. Rickerby, D.S. A review of the methods for the measurement of coating-substrate adhesion. Surf. Coat. Technol. 1988, 36, 541-557. [CrossRef]

20. Valli, J. A review of adhesion test methods for thin hard coatings. J. Vac. Sci. Technol. A Vac. Surf. Films 1986, 4, 3007-3014. [CrossRef]

21. Chalker, P.R.; Bull, S.J.; Rickerby, D.S. A review of the methods for the evaluation of coating-substrate adhesion. Mater. Sci. Eng. A 1991, 140, 583-592. [CrossRef]

22. Sinha, S.K. 180 years of scratch testing. Tribol. Int. 2006, 39, 61. [CrossRef]

23. Bull, S.J. Techniques for improving thin film adhesion. Vacuum 1992, 43, 517-520. [CrossRef]

24. Laugier, M. The development of the scratch test technique for the determination of the adhesion of coatings. Thin Solid Films 1981, 76, 289-294. [CrossRef]

25. Burnett, P.J.; Rickerby, D.S. The relationship between hardness and scratch adhession. Thin Solid Films 1987, 154, 403-416. [CrossRef]

26. Laugier, M.T. An energy approach to the adhesion of coatings using the scratch test. Thin Solid Films 1984, 117, 243-249. [CrossRef]

27. Burnett, P.J.; Rickerby, D.S. The scratch adhesion test: An elastic-plastic indentation analysis. Thin Solid Films 1988, 157, 233-254. [CrossRef]

28. Bull, S.J.; Rickerby, D.S.; Matthews, A.; Leyland, A.; Pace, A.R.; Valli, J. The use of scratch adhesion testing for the determination of interfacial adhesion: The importance of frictional drag. Surf. Coat. Technol. 1988, 36, 503-517. [CrossRef]

29. Kendall, K. The adhesion and surface energy of elastic solids. J. Phys. D Appl. Phys. 1971, 4, 1186. [CrossRef]

30. Schwarzer, N.; Duong, Q.H.; Bierwisch, N.; Favaro, G.; Fuchs, M.; Kempe, P.; Widrig, B.; Ramm, J. Optimization of the scratch test for specific coating designs. Surf. Coat. Technol. 2011, 206, 1327-1335. [CrossRef]

31. Hegadekatte, V.; Huber, N.; Kraft, O. Finite element based simulation of dry sliding wear. Model. Simul. Mater. Sci. Eng. 2005, 13, 57. [CrossRef]

32. Hegadekatte, V.; Huber, N.; Kraft, O. Modeling and simulation of wear in a pin on disc tribometer. Tribol. Lett. 2006, 24, 51. [CrossRef]

33. Steiner, L.; Bouvier, V.; May, U.; Hegadekatte, V.; Huber, N. Modelling of unlubricated oscillating sliding wear of DLC-coatings considering surface topography, oxidation and graphitisation. Wear 2010, 268, 1184-1194. [CrossRef]

34. Holmberg, K.; Ronkainen, H.; Laukkanen, A.; Wallin, K.; Erdemir, A.; Eryilmaz, O. Tribological analysis of TiN and DLC coated contacts by 3D FEM modelling and stress simulation. Wear 2008, 264, 877-884. [CrossRef]

35. Holmberg, K.; Ronkainen, H.; Laukkanen, A.; Wallin, K. Friction and wear of coated surfaces-scales, modelling and simulation of tribomechanisms. Surf. Coat. Technol. 2007, 202, 1034-1049. [CrossRef]

36. Holmberg, K.; Laukkanen, A.; Ronkainen, H.; Wallin, K.; Varjus, S.; Koskinen, J. Tribological contact analysis of a rigid ball sliding on a hard coated surface: Part I: Modelling stresses and strains. Surf. Coat. Technol. 2006, 200, 3793-3809. [CrossRef]

37. Beake, B.D.; Vishnyakov, V.M.; Valizadeh, R.; Colligon, J.S. Influence of mechanical properties on the nanoscratch behaviour of hard nanocomposite $\mathrm{SiN} / \mathrm{Si}_{3} \mathrm{~N}_{4}$ coatings on si. J. Phys. D Appl. Phys. 2006, 39, 1392. [CrossRef]

38. Beake, B.D.; Endrino, J.L.; Kimpton, C.; Fox-Rabinovich, G.S.; Veldhuis, S.C. Elevated temperature repetitive micro-scratch testing of AlCrN, TiAlN and AlTiN PVD coatings. Int. J. Refract. Met. Hard Mater. 2017, 69, 215-226. [CrossRef] 
39. Fox-Rabinovich, G.S.; Kovalev, A.I.; Aguirre, M.H.; Beake, B.D.; Yamamoto, K.; Veldhuis, S.C.; Endrino, J.L.; Wainstein, D.L.; Rashkovskiy, A.Y. Design and performance of AlTiN and TiAlCrN PVD coatings for machining of hard to cut materials. Surf. Coat. Technol. 2009, 204, 489-496. [CrossRef]

40. Bull, S.J.; Rickerby, D.S.; Robertson, T.; Hendry, A. The abrasive wear resistance of sputter ion plated titanium nitride coatings. Surf. Coat. Technol. 1988, 36, 743-754. [CrossRef]

41. Perry, A.J.; Pulker, H.K. Hardness, adhesion and abrasion resistance of $\mathrm{TiO}_{2}$ films on glass. Thin Solid Films 1985, 124, 323-333. [CrossRef]

42. Guruvenket, S.; Azzi, M.; Li, D.; Szpunar, J.A.; Martinu, L.; Klemberg-Sapieha, J.E. Structural, mechanical, tribological, and corrosion properties of a-SiC:H coatings prepared by PECVD. Surf. Coat. Technol. 2010, 204, 3358-3365. [CrossRef]

43. Borrero-López, O.; Hoffman, M.; Bendavid, A.; Martin, P.J. Mechanical properties and scratch resistance of filtered-arc-deposited titanium oxide thin films on glass. Thin Solid Films 2011, 519, 7925-7931. [CrossRef]

44. Beake, B.D.; Liskiewicz, T.W. Comparison of nano-fretting and nano-scratch tests on biomedical materials. Tribol. Int. 2013, 63, 123-131. [CrossRef]

45. Das, D.K.; Srivastava, M.P.; Joshi, S.V.; Sivakumar, R. Scratch adhesion testing of plasma-sprayed yttria-stabilized zirconia coatings. Surf. Coat. Technol. 1991, 46, 331-345. [CrossRef]

46. Chen, S.-Y.; Ma, G.-Z.; Wang, H.-D.; He, P.-F.; Wang, H.-M.; Liu, M. Evaluation of adhesion strength between amorphous splat and substrate by micro scratch method. Surf. Coat. Technol. 2018, 344, 43-51. [CrossRef]

47. Brostow, W.; Lobland, H.E.H. Materials: Introduction and Applications; John Wiley \& Sons: New York, NY, USA, 2017.

48. Sola, R. Post-treatment surface morphology effect on the wear and corrosion resistance of nitrided and nitrocarburized 41 CrAlMo7 steel. La Metall. Ital. 2010, 5, 21-31.

49. Sola, R.; Giovanardi, R.; Parigi, G.; Veronesi, P.; Berto, F. A novel methods for fracture toughness evaluation of tool steels with post-tempering cryogenic treatment. Metals 2017, 7, 75. [CrossRef]

50. Sola, R.; Poli, G.; Veronesi, P.; Giovanardi, R. Effects of surface morphology on the wear and corrosion resistance of post-treated nitrided and nitrocarburized 42CrMo4. Metall. Mater. Trans. A 2014, 45, 2827-2833. [CrossRef]

51. Jensen, H.; Jensen, U.M.; Sorensen, G. Reactively sputtered Cr nitride coatings studied using the acoustic emission scratch test technique. Surf. Coat. Technol. 1995, 74-75, 297-305. [CrossRef]

52. Yamamoto, S.; Ichimura, H. Effects of intrinsic properties of TiN coatings on acoustic emission behavior at scratch test. J. Mater. Res. 2011, 7, 2240-2247. [CrossRef]

53. Benayoun, S.; Hantzpergue, J.J.; Bouteville, A. Micro-scratch test study of TiN films grown on silicon by chemical vapor deposition. Thin Solid Films 2001, 389, 187-193. [CrossRef]

54. Yang, J.; Roa, J.; Odén, M.; Johansson-Jõesaar, M.P.; Esteve, J.; Llanes, L. Substrate surface finish effects on scratch resistance and failure mechanisms of TiN-coated hardmetals. Surf. Coat. Technol. 2015, 265, 174-184. [CrossRef]

55. Kulikovsky, V.; Vorlicek, V.; Ctvrtlik, R.; Bohac, P.; Suchanek, J.; Blahova, O.; Jastrabik, L. Mechanical and tribological properties of coatings sputtered from $\mathrm{SiC}$ target in the presence of $\mathrm{CH}_{4}$ gas. Surf. Coat. Technol. 2011, 205, 3372-3377. [CrossRef]

56. Kulikovsky, V.; Ctvrtlik, R.; Vorlicek, V.; Zelezny, V.; Bohac, P.; Jastrabik, L. Effect of air annealing on mechanical properties and structure of $\mathrm{SiC}_{\mathrm{x}} \mathrm{N}_{\mathrm{y}}$ magnetron sputtered films. Surf. Coat. Technol. 2014, 240, 76-85. [CrossRef]

57. Hoche, H.; Allebrandt, D.; Bruns, M.; Riedel, R.; Fasel, C. Relationship of chemical and structural properties with the tribological behavior of sputtered SiCN films. Surf. Coat. Technol. 2008, 202, 5567-5571. [CrossRef]

58. Zhou, Y.; Probst, D.; Thissen, A.; Kroke, E.; Riedel, R.; Hauser, R.; Hoche, H.; Broszeit, E.; Kroll, P.; Stafast, H. Hard silicon carbonitride films obtained by RF-plasma-enhanced chemical vapour deposition using the single-source precursor bis(trimethylsilyl)carbodiimide. J. Eur. Ceram. Soc. 2006, 26, 1325-1335. [CrossRef]

59. Probst, D.; Hoche, H.; Zhou, Y.; Hauser, R.; Stelzner, T.; Scheerer, H.; Broszeit, E.; Berger, C.; Riedel, R.; Stafast, H.; et al. Development of PE-CVD Si/C/N:H films for tribological and corrosive complex-load conditions. Surf. Coat. Technol. 2005, 200, 355-359. [CrossRef]

60. Wu, Y.; Zhu, S.; Zhang, Y.; Liu, T.; Rao, Y.; Luo, l.; Wang, Q. The adhesion strength and deuterium permeation property of sic films synthesized by magnetron sputtering. Int. J. Hydrogen Energy 2016, 41, 10827-10832. [CrossRef] 
61. Bhattacharyya, A.S.; Mishra, S.K. Micro/nanomechanical behavior of magnetron sputtered Si-C-N coatings through nanoindentation and scratch tests. J. Micromech. Microeng. 2011, 21, 015011. [CrossRef]

62. Nazarchuk, Z.; Skalskyi, V.; Serhiyenko, O. Acoustic Emission-Methodology and Application; Springer International Publishing: Cham, Switzerland, 2017.

63. Scruby, C.B. An introduction to acoustic emission. J. Phys. E Sci. Instrum. 1987, 20, 946. [CrossRef]

64. Stulen, F.B.; Kiefner, J.F. Evaluation of acoustic emission monitoring of buried pipelines. In Proceedings of the 1982 Ultrasonics Symposium, San Diego, CA, USA, 27-29 October 1982; pp. 898-903.

65. Lim, J. In Underground pipeline leak detection using acoustic emission and crest factor technique. In Advances in Acoustic Emission Technology; Shen, G., Wu, Z., Zhang, J., Eds.; Springer: New York, NY, USA, 2015; pp. $445-450$.

66. Bakirov, M.B.; Povarov, V.P.; Gromov, A.F.; Levchuk, V.I. Development of a technology for continuous acoustic emission monitoring of in-service damageability of metal in safety-related NPP equipment. Nucl. Energy Technol. 2015, 1, 32-36. [CrossRef]

67. Lee, J.-H.; Lee, M.-R.; Kim, J.-T.; Luk, V.; Jung, Y.-H. A study of the characteristics of the acoustic emission signals for condition monitoring of check valves in nuclear power plants. Nucl. Eng. Des. 2006, 236, 1411-1421. [CrossRef]

68. Minemura, O.; Sakata, N.; Yuyama, S.; Okamoto, T.; Maruyama, K. Acoustic emission evaluation of an arch dam during construction cooling and grouting. Constr. Build. Mater. 1998, 12, 385-392. [CrossRef]

69. Sagaidak, A.; Bardakov, V.; Elizarov, S.; Terentyev, D. The use of acoustic emission method in the modern construction. In Proceedings of the 31st Conference of the European Working Group on Acoustic Emission, Dresden, Germany, 31 September 2014.

70. Bonaccorsi, L.; Calabrese, L.; Campanella, G.; Proverbio, E. Artificial neural network analyses of AE data during long-term corrosion monitoring of a post-tensioned concrete beam. J. Acoust. Emiss. 2012, 30, 40-53.

71. Rosner, S. Acoustic emission related to drought stress response of four deciduous broad-leaved woody species. J. Acoust. Emiss. 2012, 30, 11-20.

72. Holford, K.M. Acoustic emission-basic principles and future directions. Strain 2008, 36, 51-54. [CrossRef]

73. Guo, Y.B.; Ammula, S.C. Real-time acoustic emission monitoring for surface damage in hard machining. Int. J. Mach. Tools Manuf. 2005, 45, 1622-1627. [CrossRef]

74. Julia-Schmutz, C.; Hintermann, H.E. Microscratch testing to characterize the adhesion of thin layers. Surf. Coat. Technol. 1991, 48, 1-6. [CrossRef]

75. Choudhary, R.K.; Mishra, P. Use of acoustic emission during scratch testing for understanding adhesion behavior of aluminum nitride coatings. J. Mater. Eng. Perform. 2016, 25, 2454-2461. [CrossRef]

76. Proctor, T.M. An improved piezoelectric acoustic emission transducer. J. Acoust. Soc. Am. 1982, 71, $1163-1168$. [CrossRef]

77. Turner, R.C.; Fuierer, P.A.; Newnham, R.E.; Shrout, T.R. Materials for high temperature acoustic and vibration sensors: A review. Appl. Acoust. 1994, 41, 299-324. [CrossRef]

78. Von Stebut, J.; Lapostolle, F.; Bucsa, M.; Vallen, H. Acoustic emission monitoring of single cracking events and associated damage mechanism analysis in indentation and scratch testing. Surf. Coat. Technol. 1999, 116-119, 160-171. [CrossRef]

79. Hiroyuki, K.; Akio, M.; Ken, Y.; Shigeru, N.; Yasushi, F. Analysis of AE signals during scratch test on the coated paperboard. J. Acoust. Emiss. 2012, 30,1-11.

80. Gallego, A.; Gil, J.F.; Vico, J.M.; Ruzzante, J.E.; Piotrkowski, R. Coating adherence in galvanized steel assessed by acoustic emission wavelet analysis. Scr. Mater. 2005, 52, 1069-1074. [CrossRef]

81. Gallego, A.; Gil, J.F.; Castro, E.; Piotrkowski, R. Identification of coating damage processes in corroded galvanized steel by acoustic emission wavelet analysis. Surf. Coat. Technol. 2007, 201, 4743-4756. [CrossRef]

82. Kataruka, A.; Mendu, K.; Okeoghene, O.; Puthuvelil, J.; Akono, A.-T. Microscopic assessment of bone toughness using scratch tests. Bone Rep. 2017, 6, 17-25. [CrossRef] [PubMed]

83. Ishikawa, H.; Ohnaka, T.; Hirohashi, M. Evaluation of acoustic emission generated in scratch testing of ceramic coatings. J. Surf. Finish. Soc. Jpn. 1994, 45, 296-300. [CrossRef]

84. Bhansali, K.J.; Kattamis, T.Z. Quality evaluation of coatings by automatic scratch testing. Wear 1990, 141, 59-71. [CrossRef]

85. Sekler, J.; Steinmann, P.A.; Hintermann, H.E. The scratch test: Different critical load determination techniques. Surf. Coat. Technol. 1988, 36, 519-529. [CrossRef] 
86. Piotrkowski, R.; Castro, E.; Gallego, A. Wavelet power, entropy and bispectrum applied to AE signals for damage identification and evaluation of corroded galvanized steel. Mech. Syst. Signal Process. 2009, 23, 432-445. [CrossRef]

87. Piotrkowski, R.; Gallego, A.; Castro, E.; García-Hernandez, M.T.; Ruzzante, J.E. Ti and Cr nitride coating/steel adherence assessed by acoustic emission wavelet analysis. NDT E Int. 2005, 38, 260-267. [CrossRef]

88. Griffin, J.M.; Torres, F. Dynamic precision control in single-grit scratch tests using acoustic emission signals. Int. J. Adv. Manuf. Technol. 2015, 81, 935-953. [CrossRef]

89. Griffin, J. Traceability of acoustic emission measurements for a proposed calibration method-Classification of characteristics and identification using signal analysis. Mech. Syst. Signal Process. 2015, 50-51, 757-783. [CrossRef]

90. Griffin, J.; Chen, X. Classification of the acoustic emission signals of rubbing, ploughing and cutting during single grit scratch tests. Int. J. Nanomanuf. 2006, 1, 189-209. [CrossRef]

91. Sagasta, F.; Zitto, M.E.; Piotrkowski, R.; Benavent-Climent, A.; Suarez, E.; Gallego, A. Acoustic emission energy $b$-value for local damage evaluation in reinforced concrete structures subjected to seismic loadings. Mech. Syst. Signal Process. 2018, 102, 262-277. [CrossRef]

92. Zitto, M.; Scaramal, M.; Sagasta, F.; Piotrkowski, R.; Gallego, A.; Castro, E. AE signal processing in dynamical tests of reinforced concrete structures. In Proceedings of the 30th European Conference on Acoustic Emission Testing \& 7th International Conference on Acoustic Emission, Granada, Spain, 12-15 September 2012.

93. Zhou, W.; He, Y.; Lu, X. Acoustic emission in scratch processes of metals. Insight Non-Destr. Test. Cond. Monit. 2015, 57, 635-642. [CrossRef]

94. Shiwa, M.; Weppelmann, E.R.; Bendeli, A.; Swain, M.V.; Munz, D.; Kishi, T. Acoustic emission and precision force-displacement observations of spherical indentations into TiN films on silicon. Surf. Coat. Technol. 1994, 68-69, 598-602. [CrossRef]

95. Badzian, A.; Badzian, T.; Drawl, W.D.; Roy, R. Silicon carbonitride: A rival to cubic boron nitride. Diam. Relat. Mater. 1998, 7, 1519-1525. [CrossRef]

96. An, L.; Riedel, R.; Konetschny, C.; Kleebe, H.J.; Raf, R. Newtonian viscosity of amorphous silicon carbonitride at high temperature. J. Am. Ceram. Soc. 1998, 81, 1349-1352. [CrossRef]

97. Riedel, R.; Kleebe, H.J.; Schonfelder, H.; Aldinger, F. A covalent micro nanocomposite resistant to high-temperature oxidation. Nature 1995, 374, 526-528. [CrossRef]

98. Lebedev, A.A.; Ivanov, A.M.; Strokan, N.B. Radiation resistance of SiC and nuclear-radiation detectors based on SiC films. Semiconductors 2004, 38, 125-147. [CrossRef]

99. Kulikovsky, V.; Vorlíček, V.; Boháč, P.; Stranyánek, M.; Čtvrtlík, R.; Kurdyumov, A. Mechanical properties of amorphous and microcrystalline silicon films. Thin Solid Films 2008, 516, 5368-5375. [CrossRef]

100. Kulikovsky, V.; Vorlíček, V.; Boháč, P.; Stranyánek, M.; Čtvrtlík, R.; Kurdyumov, A.; Jastrabik, L. Hardness and elastic modulus of amorphous and nanocrystalline SiC and Si films. Surf. Coat. Technol. 2008, 202, 1738-1745. [CrossRef]

101. Yang, J. A harsh environment wireless pressure sensing solution utilizing high temperature electronics. Sensors 2013, 13, 2719-2734. [CrossRef] [PubMed]

102. Riedel, R.; Kienzle, A.; Dressler, W.; Ruwisch, L.; Bill, J.; Aldinger, F. A silicoboron carbonitride ceramic stable to $2000{ }^{\circ} \mathrm{C}$. Nature 1996, 382, 796-798. [CrossRef]

103. Raj, R.; An, L.; Shah, S.; Riedel, R.; Fasel, C.; Kleebe, H.-J. Oxidation kinetics of an amorphous silicon carbonitride ceramic. J. Am. Ceram. Soc. 2001, 84, 1803-1810. [CrossRef]

104. Ctvrtlik, R.; Al-Haik, M.; Kulikovsky, V. Mechanical properties of amorphous silicon carbonitride thin films at elevated temperatures. J. Mater. Sci. 2015, 50, 1553-1564. [CrossRef]

105. Ctvrtlik, R.; Kulikovsky, V.; Vorlicek, V.; Tomastik, J.; Drahokoupil, J.; Jastrabik, L. Mechanical properties and microstructural characterization of amorphous $\mathrm{SiC}_{x} \mathrm{~N}_{y}$ thin films after annealing beyond $1100{ }^{\circ} \mathrm{C}$. J. Am. Ceram. Soc. 2016, 99, 996-1005. [CrossRef]

106. Goldstein, J.; Newbury, D.E.; Joy, D.C.; Lyman, C.E.; Echlin, P.; Lifshin, E.; Sawyer, L.; Michael, J.R. Scanning Electron Microscopy and X-ray Microanalysis, 3rd ed.; Springer Science + Business Media: New York, NY, USA, 2003; p. 689.

(C) 2018 by the authors. Licensee MDPI, Basel, Switzerland. This article is an open access article distributed under the terms and conditions of the Creative Commons Attribution (CC BY) license (http:/ / creativecommons.org/licenses/by/4.0/). 